\title{
Analysis of Achievement Motivation and Academic Engagement of Students in the Nigerian Classroom
}

\author{
Imaobong D. Akpan Ph.D \\ Department of Educational Foundations, Guidance and Counselling, \\ University Of Uyo, Uyo, Nigeria \\ e-mail: imaobongakpan@uniuyo.edu.ng \\ Mfonobong E. Umobong Ph.D \\ Department of Educational Foundations, Guidance and Counselling, \\ University Of Uyo, Uyo, Nigeria \\ e-mail: mfonobongumobong@uniuyo.edu.ng
}

Doi:10.5901/ajis.2013.v2n3p385

\begin{abstract}
Motivating students so that they can succeed in school is one of the greatest challenges of this century. Getting students to learn and sustaining their interest in what they are learning is one of the major objectives of teachers in the classroom. This study therefore attempts to determine the impact of achievement motivation on students' academic engagement. Three hypotheses were stated. Using Achievement Motivation and Academic Engagement questionnaire administered on 540 senior secondary students' data was generated for the study. Analysis of the data revealed that achievement motivation has a significant impact on academic engagement with highly motivated students being more academically engaged than the moderately and lowly motivated students. Also result revealed that male students were more motivated than female student and, age also had a significant influence on achievement motivation. Based on this result, recommendations were made on how to raise the achievement motivation of students in order to get them more engaged in school work.
\end{abstract}

Keywords: Motivation, Achievement Motivation, Academic Engagement, Academic Success

\section{Introduction}

Globally, there has been an increasing concern in the Education sector on how to ensure that students learn optimally at school and achieve academic excellence in their academic pursuit. In Nigeria, there has been a nationwide cry on the fallen standards of education. Various factors have been identified for low academic achievement among students and these include poor study habit, laziness, ineffective classroom instructions and inadequate provision of needs among others (Akpan, 2000). It has been noticed that some students in the classroom do not pay attention to what the teacher is doing as they are easily caught engaged in other activities. Jones (2008) observes that it is easy to see students slouched in their chairs and not listening to the teacher or participating in the classroom discussion which portrays lack of engagement. Motivating students to learn in school is a topic of great concern for educationist today and motivating students so that they can succeed in school is one of the greatest challenges of this century (Awan, Noureen and Nas, 2011). According to the authors, lack of motivation is a big hurdle in learning and a pertinent cause in the deterioration of education standards. Getting students to learn and sustaining their interest in what they are learning therefore should be the sole objective of teachers in the classroom.

Motivation is a strong force in achievement. Moula (2010) observes that motivation is one of the factors that contribute to academic success; that parents and educators should strive to understand the importance of promoting and encouraging academic motivation early in life. Feldman (2005) refers to motivation as factors that direct and energize the behavior of humans and other organisms, while Wood (2002) sees motivation as a process that initiates, directs, and sustains behaviours to satisfy physiological or psychological needs. Motivation is also seen as what gets one going, keeps one going, and determines where one is going (Slarin, 2006). Motivations are of two major types, intrinsic and extrinsic. Intrinsic motivation is based on the internal factors such as self-determination, effort, challenge and curiosity while extrinsic motivation incorporates external factors such as rewards and punishment (Santrock, 2005).

Furrer and Skinner (2003) see engagement as referring to active, goal-directed, flexible, constructive, persistent, 
focused interactions with the social and physical environments. Engagement in school (academic engagement) is said to be an important academic outcome in its own right as it improves performance and validates positive expectations about academic abilities, as well as a good predictor of children's long-term academic achievement (Skinner, Zimmer-Gembeck \& Connell, 1998); and their eventual completion of school (Connell, Spencer \& Aber, 1994). Motivation and academic engagement among students has been the focus of many researchers in a bid to improve the classroom performance of students (Martin, 2009, 2010; Jones 2008; Green, Martin and Marsh, 2007). In summary, Martin (2010) sees motivation as students' energy and drive to learn and to work hard at school, while engagement is the behavior that reflects this energy and drive.

Achievement motivation has been defined as the extent to which individuals differ in their need to strive to attain rewards, such as physical satisfaction, praise from others and feelings of personal mastery (Mc Clelland, 1985). Individuals with high achievement motives usually act in ways that will enable them to outperform others, meeting or surpassing some standards of excellence or do something unusual (Schmidt \& Frieze, 1997). All students are influenced by a need to achieve to a certain degree (Awan et al, 2011). Those students, who had a high desire of success, work hard to achieve (Zenzen, 2002). Achievement motivation could be seen as self- determination to success in whatever activities one engages in, be it academic work, professional work, sporting events, among others (Tella, 2007). Gestinde (2000) points out that the urge to achieve varies from one individual to another while the need to achieve is very high in some individuals, it may be very low for others based on socialization processes and learning experiences. David Mc Clelland is most noted with the modern study of achievement motivation. He and his associates coined the term n-Ach which denotes need for achievement (Mc Clelland, 1961; Mc Clelland \& Winter, 1969). This theory states that people will do what they have been rewarded for doing under appropriate conditions. This theory deals with the perceived causes of success and failure, the characteristics of causal thinking and subsequent emotional experiences in relation to achievement behaviours (Awan et al, 2011). Moula (2010) links academic to achievement motivation and sees this as the need or desire to excel in academic work as people who are motivated are likely to perform well in their examinations.

It has been observed that high (secondary) school is a low point in student engagement, despite being a critical time for developing the skills necessary to thrive in the adult world (Seidman \& French, 1997). In addition, both intrinsic (i.e. learning for enjoyment) and extrinsic (i.e. learning as a means to an-end) motivations decrease across the high school transition (Otis, Grouzet, \& Pelletier, 2005) and are lower than those of both elementary and college students (Martin, 2009). In a person-centred investigation of academic motivation, performance, and engagement in a high school setting, a group of researchers examined how academic performance and school engagement were associated with motivational profiles (Wormington, Corpus \& Anderson, 2011). The result indicated that as regards performance, students with high quantity and good quality motivation was equally successful and that motivational profiles may be differentially adaptive for different age groups.

In a study on impact of motivation on students' academic achievement and learning outcomes in mathematics among secondary school students in Nigeria, Tella (2007) discovered that gender difference were significant when impact of motivation on academic achievement was compared in male and female students. In addition, other result indicates significant difference when extent of motivation was taken as variables of interest on academic achievement in mathematics based on the degree of their motivation.

Cheung (1998) carried out a study in which he hypothesized that conceptions of success of achievement goal affect both inclination to and actual performance. A sample of 673 Chinese adolescents was used in testing the hypothesis. The result indicated sex differences in the conception of success. As part of larger project concerned with motivation factors in educational attainment of Asian girls, Siana, Ligthbody, Stock, and David used 985 secondary school students in London and England as their sample. They found that Asian students of both sexes rated parents and friends as more important in contributing to academic success. In another study, Skaalvik and Skaalvik (2006) revealed significant relationship between academic performance and motivation. In Nigeria, a study carried out by Ajayi (1999) on achievement motivation using 276 students revealed that there is an agreement between academic performance and motivation.

Awan, Noureen and Naz (2011) examined achievement and its relationship with achievement motivation and self concept. The sample consisted of 336 secondary schools (146 males and 172 females). The results revealed that achievement motivation and self concept are significantly related to academic achievement. Significant gender differences were discovered which were in favour of girls.

Based on the review of the above literature, achievement motivation can be perceived as a force that induces action for success. When students are properly directed and energized, they can be motivated to achieve academically which in turn enhances academic engagement for academic success. The studies examined have concentrated on 
establishing the relationship between achievement motivation and academic performance. There is however paucity of literature on the effects of achievement motivation on academic engagement especially in Nigeria. In line with this proposition, the study is carried out to investigate the impact of achievement motivation on academic engagement of students in Nigerian classroom. This study thus examined the impact of achievement motivation on academic engagement of students in the Nigerian context. The influence of gender and age on achievement motivation of students was also determined.

\section{Hypotheses}

To guide the study, three null hypotheses were formulated and tested at 0.05 level of significance.

- $\mathrm{H}_{0} 1$ Achievement motivation has no significant impact on academic engagement of students in Nigerian classroom.

- Ho2 Gender has no significant influence on achievement motivation of students in Nigerian classroom.

- Ho3 Age has no significant influence on achievement motivation of students in Nigerian classroom.

\section{Methodology}

Design: The research design adopted for this study was an ex-post facto research. The reason being that the researchers did not have direct control over the independent variables since their manifestations have already occurred and they cannot be easily manipulated.

Population: The population for this study comprised all senior secondary students of Akwa Ibom State in Nigeria.

Sampling Technique and Sample: The sample for this study consisted of five hundred and forty (540) adolescent randomly drawn using multi-stage stratified random sampling technique from schools in Akwa Ibom State. Three senatorial districts are identified in the state and were used as the first stratum. From the three senatorial districts, three local governments were each selected making a total of 9 and from each local government area, two schools were randomly selected. From the eighteen schools, 10 students were selected from each class of SS1, SS2 and SS3 making a total of 30 students from each school and a total sample size of 540 . The study includes males and females whose age ranged from 12 to 22 years with a mean age range of 15.65 years.

Instrumentation: The instrument for the study was a researcher constructed questionnaire named Achievement Motivation and Academic Engagement Questionnaire (AMAEQ). Items in the instrument that measured achievement motivation and academic engagement were constructed by the researchers. The instrument was divided into two parts, the first part sought information on the respondents demographic data like sex, age, class, and school, while the second part consisted of two sections. Section 1 contained 15 items for measuring achievement motivation (e.g "I always have great satisfaction after a job well done"). The students rated each item on a 4 point Likert type scale of very untrue of me 1 , untrue of me 2, true of me 3 , and very true of me 4 . The second section contained 12 items that measured academic engagement. Students were instructed to evaluate their academic engagement using a four point modified Likert scale, ranging from 1 (strongly disagreed) to 4 (strongly agreed). The instrument was face validated by experts in measurement and evaluation and was adjured to be content valid. The reliability of the instruments was determined by pre-testing it on 50 respondents who did not form part of the sampled respondents and internal consistency reliability using Cronbach alpha was calculated. The reliability coefficient of 0.87 and 0.81 were obtained for achievement motivation and academic engagement respectively.

Data Collection Procedure: The researchers visited the participating schools and the students were asked to assemble in their assembly hall where the questionnaires were distributed. With the assistance of the teachers in the various schools, instructions on how to respond to the questionnaire were read to the respondents. This was to ensure that the questionnaires were properly filled. After properly filing the questionnaire, it was collected on the spot from the respondents thus ensuring a $100 \%$ return rate.

\section{Results}

Data collected for the study were analyzed using inferential statistics of t-test and analysis of variance to test the three hypotheses stated for the study and was tested for significance at the 0.05 level. The results are presented hypothesis by hypothesis.

Hypothesis 1: This hypothesis stated that achievement motivation has no significant impact on academic 
engagement of students in Nigerian classroom. To test this hypothesis, students' scores on the achievement motivation scale was divided into 3 groups of highly motivated, moderately motivated and lowly motivated and an Analysis of variance (ANOVA) was used in testing the impact of these three different groups on students' academic engagement and the result is as presented on table 1.

Table 1: Analysis of variance (ANOVA) of the impact of levels of achievement motivation on academic engagement

\begin{tabular}{lccc}
\hline Levels of achievement Motivation & N & X & SD \\
\hline Lowly Motivated & 66 & 20.74 & 2.20 \\
Moderately Motivated & 294 & 26.45 & 1.92 \\
Highly Motivated & 180 & 34.83 & 4.35 \\
Total & 540 & 28.54 & 5.65 \\
\hline
\end{tabular}

\begin{tabular}{lcccc}
\multicolumn{5}{c}{ Anova } \\
\hline Source of Variance & SS & $d t$ & MS & $\boldsymbol{F}$ \\
\hline Between group & 2 & 12431.68 & 6215.84 & $698.56^{*}$ \\
Within group & 536 & 4778.25 & 8.90 & \\
Total & 539 & 17209.93 & & \\
\hline Pol
\end{tabular}

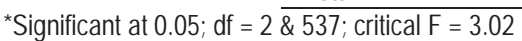

Result as presented reveals that there is a significant impact of levels of achievement motivation on students academic engagement $\left[F_{(2, \& 537)}=698.56 ; p<0.05\right]$. This result suggests that there are significant differences in academic engagement of highly motivated, moderately motivated and lowly motivated students. Result further reveals that highly motivated students $(X=34.83, S D=4.35)$ were more academically engaged followed by moderately motivated students $(X=26.45 ; S D=1.92)$ while lowly moderated students $(X=20.74 ; S D=2.20)$ were less academically engaged.

Hypothesis 2: This hypothesis stated that gender has no significant influence on achievement motivation of students in Nigerian classroom. The result of testing this hypothesis using t-test is presented in Table 2.

Table 2: Independent t-Test Analysis of the Influence of Gender on Academic Engagement of Students.

\begin{tabular}{cccccc}
\hline Gender & $\mathbf{N}$ & $\mathbf{X}$ & SD & $\mathbf{t}$ \\
\cline { 2 - 6 } Male & 227 & 47.74 & 4.31 & \multirow{2}{*}{$8.85^{\star}$} \\
Female & 313 & 43.57 & 6.07 & \\
\hline
\end{tabular}

*Significant at $0.05 ; \mathrm{df}=538$; critical $\mathrm{t}=1.96$

Table 2 presents the result of the analysis of the difference in gender on achievement motivation. The result clearly reveals that significant difference exists in the achievement motivation of male and female students ( $t_{c a l}=8.85$; $t_{c r i t}=1.96$; $\mathrm{df}=538$ at 0.05 alpha level). This leads to the rejection of the null hypothesis while the alternate hypothesis was upheld. Result further reveals that male students $(X=47.74 ; S D=4.31)$ were more highly motivated than their female counterparts $(X=43.57 ; \mathrm{SD}=6.07)$.

Hypothesis 3: Age has no significant influence on achievement motivation of students in Nigerian classroom. Testing this hypothesis using analysis of variance resulted in an F-ratio of 84.49 which was found to be significant at 0.05 with 2 and 537 degrees of freedom (See Table 3). This led to the rejection of the null hypothesis and upholding the alternative hypothesis which states that there is a significant difference in achievement motivation based on age. Table 3 further reveals that students aged between 18 and above were more achievement motivated $(X=48.41 ; S D=4.09)$; followed by those within the age limit of $15-17$ years $(X=45.03 ; S D=5.15)$ and those within the age limit of $12-14$ years $(X=40.13 ; S D=6.29)$ were less achievement motivated.

Table 3: Analysis of Variance (ANOVA) of the Influence of Age of Students on Achievement Motivation.

\begin{tabular}{cccc}
\hline Age Levels & $\mathbf{N}$ & $\mathbf{X}$ & $\mathbf{S D}$ \\
\hline $12-14$ years & 94 & 40.13 & 6.29 \\
$15-17$ & 263 & 45.03 & 5.15 \\
18 and above yrs & 183 & 48.41 & 4,09 \\
Total & 540 & 45.32 & 5.78 \\
\hline
\end{tabular}




\begin{tabular}{llllll}
\multicolumn{5}{c}{ Anova } \\
\cline { 2 - 6 } & Source of Variation & SS & dt & MS & $\boldsymbol{F}$ \\
\cline { 2 - 6 } & Between group & 4302.86 & 2 & 2151.43 & 84.49 \\
Within groups & 13673.42 & 537 & 25.46 & \\
Total & 17976.29 & 539 & & \\
\cline { 2 - 6 }
\end{tabular}

*Significant at $0.05 ; \mathrm{df}=2, \& 537$; critical $\mathrm{F}=3.02$

\section{Discussion}

The result portrays that level of achievement motivation has a significant impact on academic engagement of students. A greater number of students in the study were moderately motivated (294), some were highly motivated (180), while the least number (66) were lowly motivated. In addition, students who were highly motivated were the most academically engaged in the group, followed by those who were moderately motivated and lastly by those who were lowly motivated. This result is in agreement with previous studies Wormington et al., (2011); Skaalvik et al, (2006) and Awan et al., (2011). Wormington et al., (2011) also found out that students with high quantity and good quality motivation were equally successful, while Skaalvik et al. (2006) revealed a significant relationship between academic performance and motivation. Research findings of Awan et al. (2011) also revealed that achievement motivation and self concept are significantly related to academic achievement. Academic success, academic performance and academic achievement are all indicators of academic engagement. A child, who is successful in school, possesses a high academic performance or achievement must be academically engaged as academic engagement is required for success in school.

It was also found out in the study that gender has a significant influence on achievement motivation of students, with males being more highly motivated than females. This result is in agreement with the study of Tella (2007) who discovered that gender differences were significant when impact of motivation on academic achievement was compared in male and female students. Cheung (1998) also confirmed sex differences in the conceptions of success in achievement goal of Chinese adolescents. Moreover, Awan et al (2011) revealed that significant gender differences existed when achievement motivation and self concept were related to achievement in English and Mathematics which were however in favour of the male gender as the preferred sex. This attracts more attention and care to the male child which also fosters achievement motivation.

Finally, the result of the study also portrayed a significant influence of age on achievement motivation of students, with older students being more achievement motivated than others. This result is in line with the findings of Wormington et al. (2011) which revealed that motivational profiles may be differentially adaptive for different age groups. In the present study, students in the group of late adolescents were found to be the most achievement motivated, followed by those in the middle adolescence period and lastly, those in the early period of adolescence. Recently, Nigerian children enter secondary schools very early in life, when they are not yet matured or ready for school. This group of students has problems with school adjustment and may not be properly matured to learn which results in academic disengagement.

\section{Conclusion and Recommendations}

Based on the results of the study, it can be concluded that achievement motivation has a great impact on academic engagement, that when students are motivated, they become engaged in academic work, which eventually results in good academic performance, or success. Getting students achievement motivated to enable them deal with academic setbacks, stress and pressures is a major challenge in the Nigerian classroom. The following recommendations are hereby made to increase the level of achievement motivation in students for proper academic engagement and subsequent achievement, performance or success in the Nigerian classroom:

1. Parents and guardians should inculcate the desire to achieve early in the life of their children by providing adequately for their needs, as well as encouraging them both intrinsically and extrinsically to achieve their goals.

2. Teachers must show concern for students' low level of performance in the classroom. They must begin to reflect on the factors that contribute to students engagement and use motivational strategies to involve students in academic activities for improvement of their levels of achievement.

3. Educators as well as policy formulators must re-examine grading policies both at the school wide and classroom level to ensure that the reward system provides a situation in which students are encouraged to work hard. 
4. Classroom teachers should use rewards and incentives appropriately. The goal for these strategies should be to build a stronger student perspective on intrinsic motivation as an incentive for learning, such as the pride of completing a difficult task or the satisfaction derived from a job well done.

5. The government and school proprietors should pay attention to creating the ideal classroom environment. Classrooms should be physically comfortable for students with respect to temperature, space, furniture, and structural organization; as well as mentally stimulating with attractive displays.

6. Good interpersonal relationships between students and staff (both teachers and non-teaching) as well as among the students should be encouraged as this enhances achievement motivation as well as proper academic engagement for academic success.

\section{References}

Ajayi, I. A. (1999). Analysis of Teachers' Job Performance and Secondary School Students Achievement and their Relationship. African Journal of Educational Research, 5(2), 85 - 98.

Akpan, I. D. (2000). Single Parenting and Social Adjustment of Adolescent Students. University of Uyo Journal of Women Academics (UJOWACS). 1(1), $164-125$.

Awan, R, Noureen, G., Naz, A. (2011). A Study of Relationship between Achievement Motivation, Self concept and Achievement in English and Mathematics at Secondary level. International Education Studies, 4(3), $72-78$.

Cheung, C. (1998). Conceptions of success. Their correlates with Pro-social Orientation and Behaviour in Chinese Adolescents. Journal of Adolescence, 21(1), 31-42.

Feldman, R. S. (2005). Understanding Psychology $7^{\text {th }}$ E. New York: McGraw Hill Higher Education.

Furrer, C., Skinner, E. (2003). Sense of relatedness as a factor in children's academic engagement and performance. Journal of Educational Psychology, 95(1), 148-162.

Green, J. Martin, A. J., \& Marsh, H. W. (2007). Academic Motivation and Engagement: A Domain Specific Approach. Self Research Centre, University of Western Sydney, Australia. http://www.aare.edu.au/05pap/gre0584.pdf.

Jones, R. D. (2008). Strengthening Student Engagement. International Center for Leadership in Education.

Martin, A. J. (2010) Girls, Achievement Motivation and the Glass Ceiling. Implications for Personal Potential. Lifelong Achievement Group. www.lifelongachievement.com

Martin, A. J.(2009). The Motivation and Engagement Scale. Sydney: Lifelong Achievement Group. www.lifelongacheievement.com

McClelland, D. C. \& Winter, D. G. (1969). Motivating Economic Achievement. New York: Free Press.

McClelland, D. C. (1961). The Achieving Society. Princeton, New Jersey: Van Nostrand.

McClelland, D. C. (1985). Human Motivation. Chicago: Scott Foresman.

Muola, J. M. (2010). A Study of the Relationship between Academic Achievement Motivation and Home Environment among Standard Eight Pupils. Educational Research and Reviews, 5(5), 213-217.

Otis, N., Grouzet, F. M., Pelletier, L. G. (2005). Latent Motivational Change in an Academic Setting: A 3-year Longitudinal Study. Journal of Educational Psychology, 97, 170-183.

Santrock, J. W. (2005). Adolescence. New York: McGraw Hill.

Seidman, E., French, S. E. (1997). Normative School Transitions among Urban Adolescents: When, Where, and How to Intervene. In H. J. Wahlberg \& O. Reyes (Eds.), Children and Youth: Interdisciplinary Perpectives (166-189). Thousand Oaks, Ca: Sage Publications.

Siana, G., Ligthbody, P., Stock, R., \& Walsh, D. (1998). Motivation and Attribution at Secondary Schools. The Role of Ethnic Group. Gender Education, 8(3), 261-274.

Skaalvik, S., Skaalvik, E. M. (2006). Self-concept and Self-efficacy in Mathematics: Relation with Mathematics Motivation and Achievement. Proceedings of the International Conference on Learning Sciences; Bloomington, Indiana. Available at: http://findarticles.com (Assessed 07/09/2006).

Skinner, E. A., Zimmer-Gembeck, M. J., \& Connell, J. P. (1998). Individual Differences and the Development of Perceived Control. Monographs of the society for Research in Child Development, 63(2-3), Whole No. 204.

Slavin, D. (2006). The Educational Psychology: Theory into Practice. Eaglewood Cliff, N. J.: Prentice Hall.

Tella, A. (2007). The Impact of Motivation on Students' Academic Achievement and Learning Outcomes in Mathematics among Secondary School Students in Nigeria. Eurasia Journal of Mathematics, Science and Technology Education, 3(2), 149-156.

Wood, W. (2002). Sunday Guide for the World of Psychology $4^{\text {th }}$ ed. Boston: Allyn and Bacon.

Wormington, S. V., Corpus, J. H., \& Anderson, K. G. (2011). Running Head: Motivation in High School. A Person-centred Investigation of Academic Motivation, Performance, Engagement in a High School Setting. Paper Presented at the Annual Meeting of the American Educational Research Association. New Orleans, LA. 